\title{
DAMPING INDUCED BY DRY FRICTION: ANALYSES AND EXPERIMENTS FOR MODELING IMPROVEMENT
}

\author{
M.A. Douville, B. Faverjon, E. Chatelet, G. Jacquet-Richardet \\ ${ }^{1}$ Université de Lyon, CNRS, INSA-Lyon, LaMCoS, \\ UMR5259, France F-69621LaMCoS \\ e-mail: georges.jacquet@insa-lyon.fr
}

Keywords: Vibration, Friction, Nonlinear behavior, Experiment, Modelling.

\begin{abstract}
The present study deals with the effects of contact characteristics on the vibratory response of a beam associated with several rubbing devices. Experimentally different contact configurations are tested by varying the contact area size and roughness of samples. For each tests, the frequency response functions (FRF) are measured and compared. Numerically, temporal calculations are presented and compared to measured data, using Masing's contact model with updated parameter values and averaged estimated values.
\end{abstract}




\section{INTRODUCTION}

The optimization of the vibratory response of structures in presence of rubbing is always very delicate due to the highly nonlinear behavior induced by dry friction occurring at the interfaces. Sticking, macro or micro slipping between interfaces have major effects on both natural frequencies and damping properties.

Due to the diversity of contact configurations, friction models are often very case dependent and cannot be efficiently used without identifying: the type of friction occurring at the interfaces (based on the shape of the hysteresis curve) and contact parameters such as friction coefficient or joint stiffness. Those information may be obtained from specific experimental analyses or from available databases. In [1] for example, the authors propose estimated friction coefficients and contact stiffness values based on a very large experimental campaign they carried.

There is always a need for better understanding of rubbing mechanisms leading to optimal configurations and for more physics-based models than the classical and simple Coulomb or Masing models. A promising way concerns models that take into account material and geometrical properties of contacting surfaces, surface roughness data, and contact loading [2-4]. These models are based on the pioneer work of Greenwood and Williamson on rough contacts [5]. Knowing the behavior of an individual spherical asperity pressed against a flat surface it is possible, thanks to statistical summation, to simulate the global behavior of two rough flaton-flat rubbing surfaces.

In the present study, a test rig has been developed to measure the dynamic response of a steel beam associated with several friction configurations. The set-up allows punctual or surface to surface contact cases. In the case of surface to surface contact, devices with various area size, shape and roughness were tested in order to assess their influence on the overall response. Numerically, temporal calculations are presented and compared to the measured data using different contact models with updated parameter values and averaged estimated values.

\section{THE TEST RIG}

The studied structure is a cantilever steel beam with a rectangular cross section of $0.008 \mathrm{~m}$ by $0.04 \mathrm{~m}$ and a length of $0.50 \mathrm{~m}$. At the free end, the beam may be associated with different rubbing devices (Figure 1).

The experimental set-up allows the measurement of the displacement at $0.35 \mathrm{~m}$ of the clamped end of the beam by mean of an accelerometer (measured signal integrated twice). The excitation force provided by a shaker is measured by a force sensor located at the end of the shaker's push rod. The normal and tangential contact forces are also given by a force sensor. Two categories of devices were chosen in order to allow punctual contacts or surface to surface contacts (Figure 2). Sine sweeps (harmonic excitation) were performed at constant excitation force amplitude within the [15-130] Hz frequency range and for various normal contact forces. 


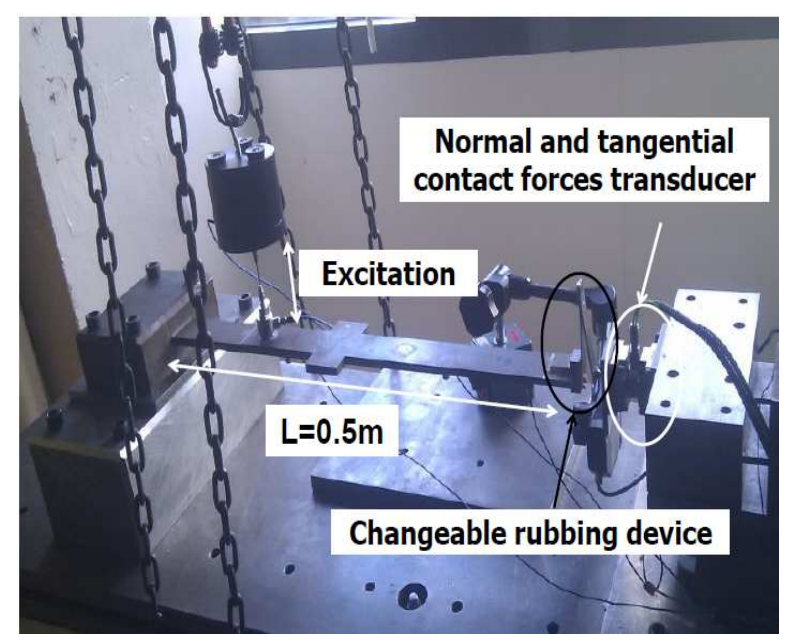

Figure 1: Experimental set up - cantilever steel beam.

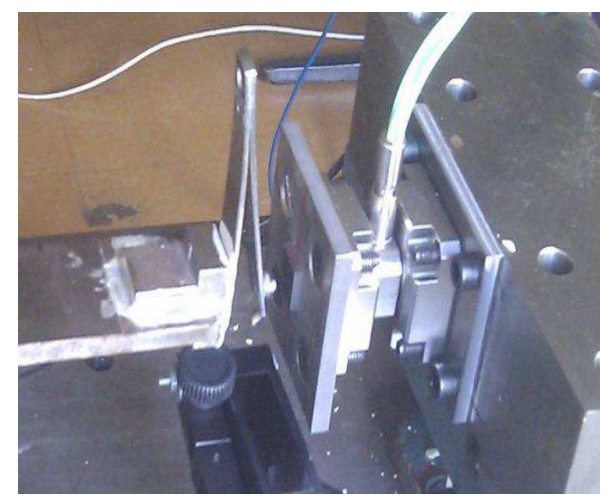

a) Punctual contact

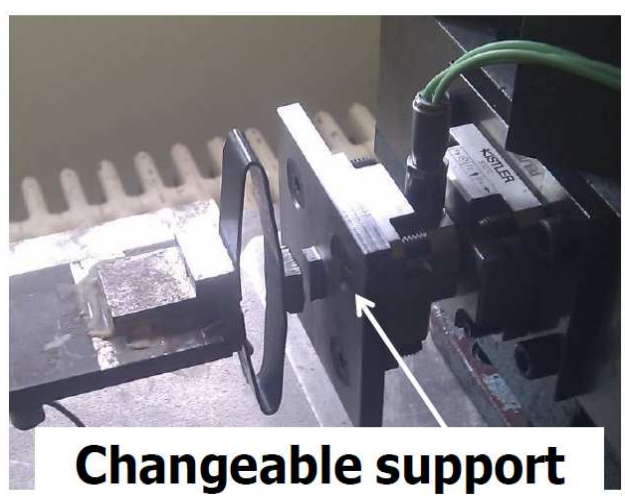

b) Surface to surface contact

Figure 2: Rubbing devices.

Figure 3 gives an example of typical measured FRFs for the punctual contact case. The classical influence of normal contact load is exhibited.

For a high normal load $(\mathrm{Fn}=40 \mathrm{~N}$ associated to an excitation force of $2 \mathrm{~N})$ contact is stuck. The FRF exhibits a linear behaviour with a peak resonance at $86 \mathrm{~Hz}$. As the normal load is lowered (from $30 \mathrm{~N}$ to $0.25 \mathrm{~N}$ ) relative displacement is allowed at the contact (presence of stick/slip) and vibrational amplitudes around the $86 \mathrm{~Hz}$ resonance peak are damped, becoming nearly flat. Finally, for $\mathrm{Fn}=0.1 \mathrm{~N}$ contact is in a slip state and a high resonance peak is again observed at $24 \mathrm{~Hz}$ (free configuration).

In Figure 4, an example of the measured tangential forces in stick and stick/slip states is shown. When contact is stuck, the tangential force is proportional to displacement (sinusoidal signal). On the other hand, when contact is in a stick/slip state, the tangential force is proportional to displacement in the stuck phase and keep the limit value of $\pm \mu F n$ ( $\mu$ friction coefficient) in the slip phase. 


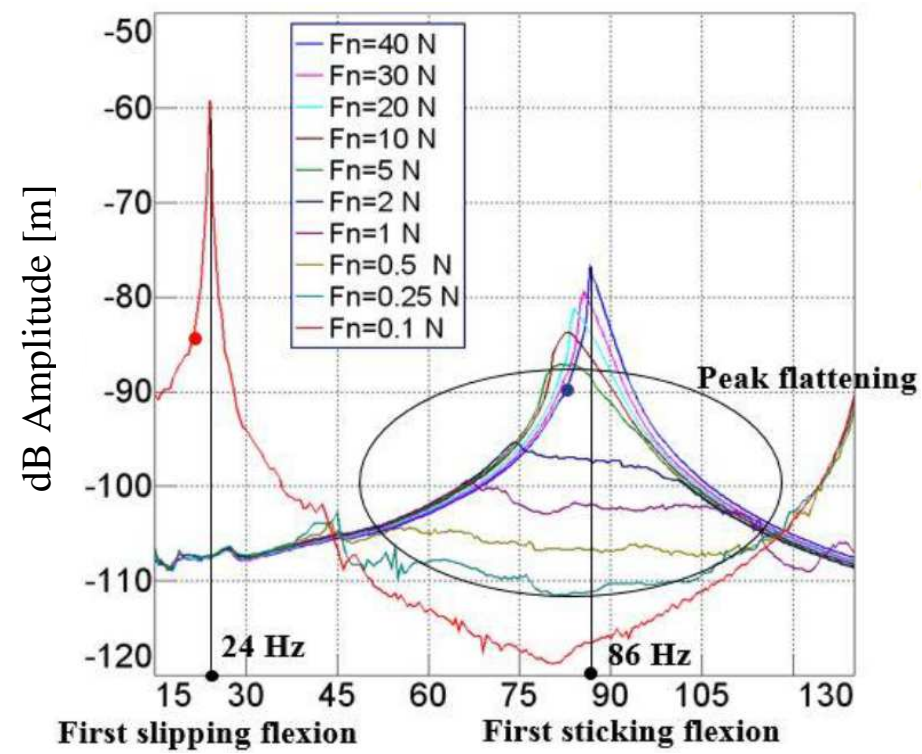

Figure 3: FRF vs normal load.

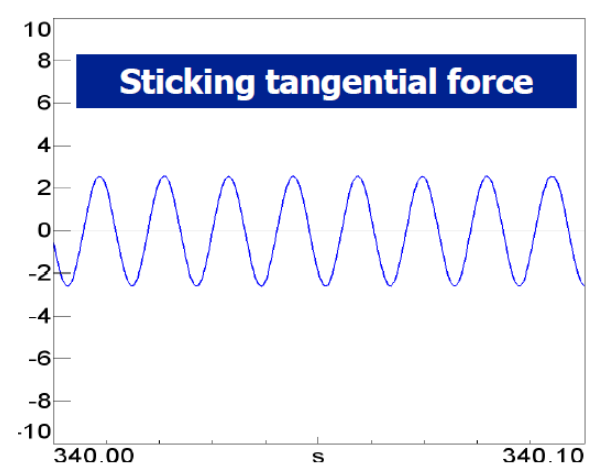

a) Stick contact state

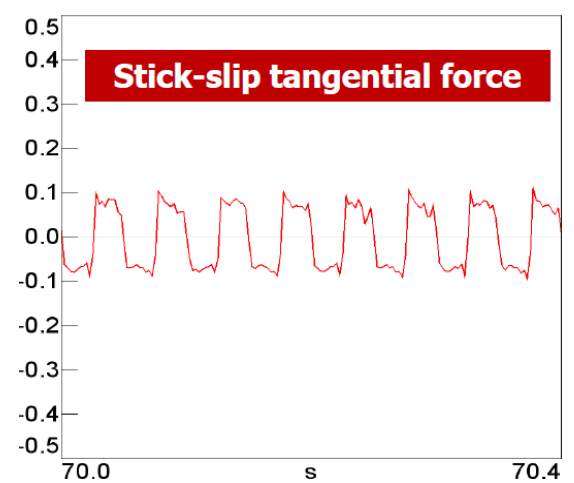

b) Stick/slip contact state

Figure 4 : Measured tangential force.

\section{DYNAMIC RESPONSE OF THE STRUCTURE}

Only the results associated to surface to surface contact configurations are presented here. The different samples considered were made of various contact areas $\left(13 \times 13 \mathrm{~mm}^{2}, 9 \times 9 \mathrm{~mm}^{2}\right.$, $13 \times 5 \mathrm{~mm}^{2}, 5 \times 5 \mathrm{~mm}^{2}$, Figure 5) and two surface finish, one rough and one smooth. Surface finish is described by the average roughness (Ra) defined in [6]:

$$
R_{a}=\frac{1}{L} \int_{0}^{L}|z(x)| d x
$$

where $z(x)$ represents the height of asperities and L the sampling length.

In Figure 6, the profiles of the $13 \times 13 \mathrm{~mm}^{2}$ samples are presented. The smooth one has a $\mathrm{Ra}$ of $0.714 \mu \mathrm{m}$ while the rough one has a $\mathrm{Ra}$ of $3.76 \mu \mathrm{m}$. Regarding the external forces, nor- 
mal loads were varied within the range $[0.1-80] \mathrm{N}$ and the excitation force amplitude remained at $2 \mathrm{~N}$.

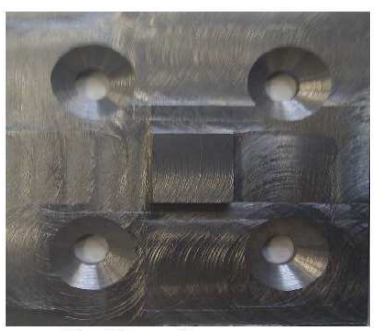

$13 \times 13 \mathrm{~mm}^{2}$

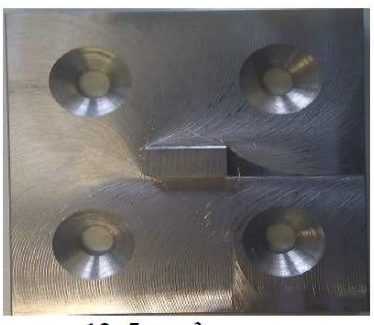

$13 \times 5 \mathrm{~mm}^{2}$

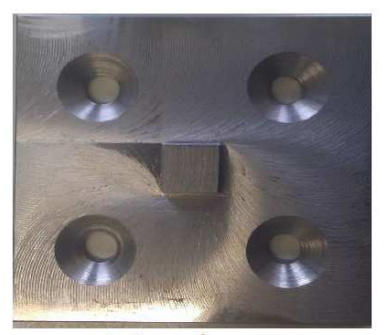

$9 \times 9 \mathbf{m m}^{2}$

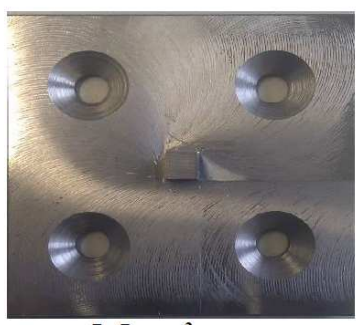

$5 \times 5 \mathrm{~mm}^{2}$

Figure 5: Samples

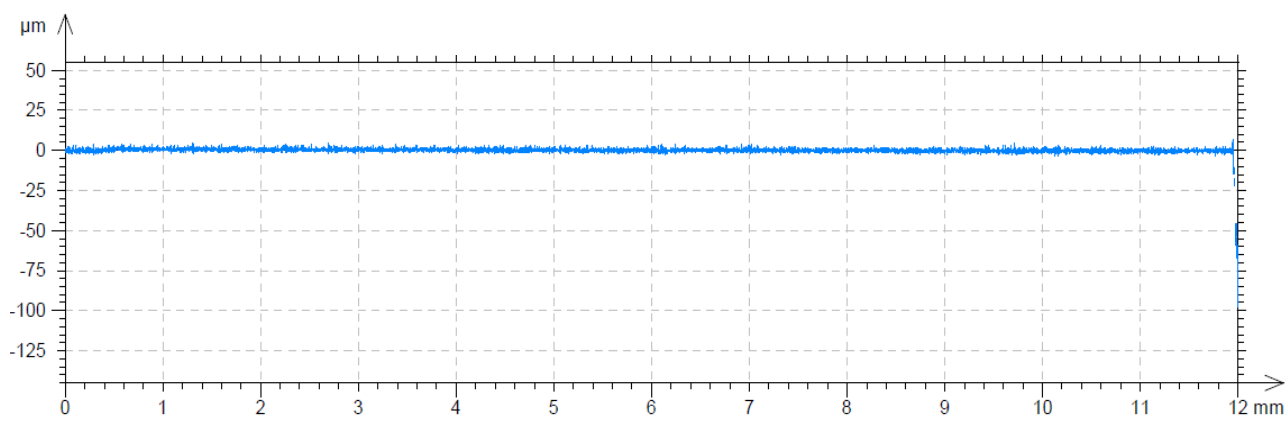

a) Profile of the smooth $13 \times 13 \mathrm{~mm}^{2}$ sample : $\mathrm{Ra}=0.714 \mu \mathrm{m}$

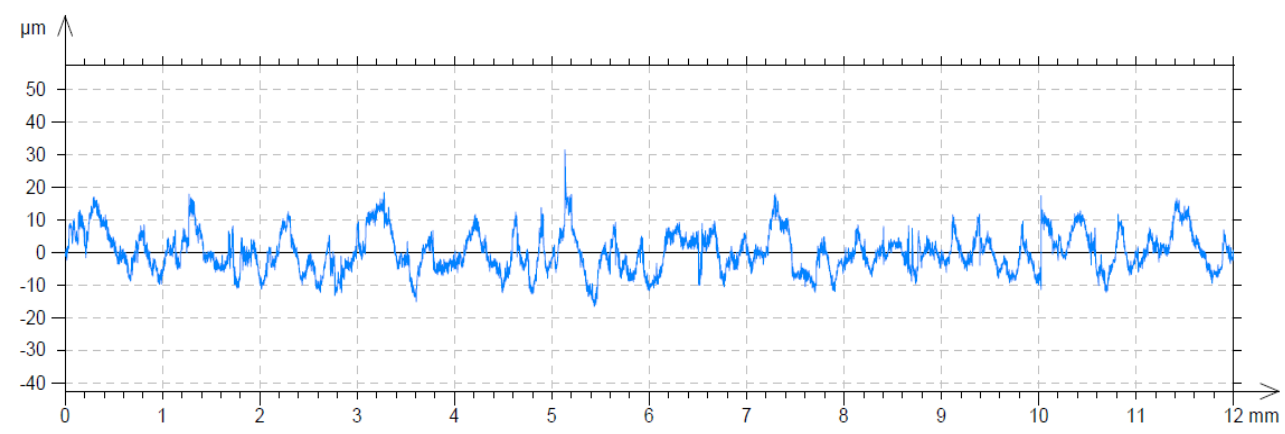

b) Profile of rough $13 \times 13 \mathrm{~mm}^{2}$ sample : $\mathrm{Ra}=3.76 \mu \mathrm{m}$

Figure 6: Profiles of the $13 \times 13 \mathrm{~mm}^{2}$ specimens.

Figure 7 gives the FRFs associated to the four smooth samples for a normal load of $2 \mathrm{~N}$. As clearly shown responses are identical and contact area size does not affect significantly the dynamics of the assembly. The same observations were made when assessing the influence of surface roughness. 


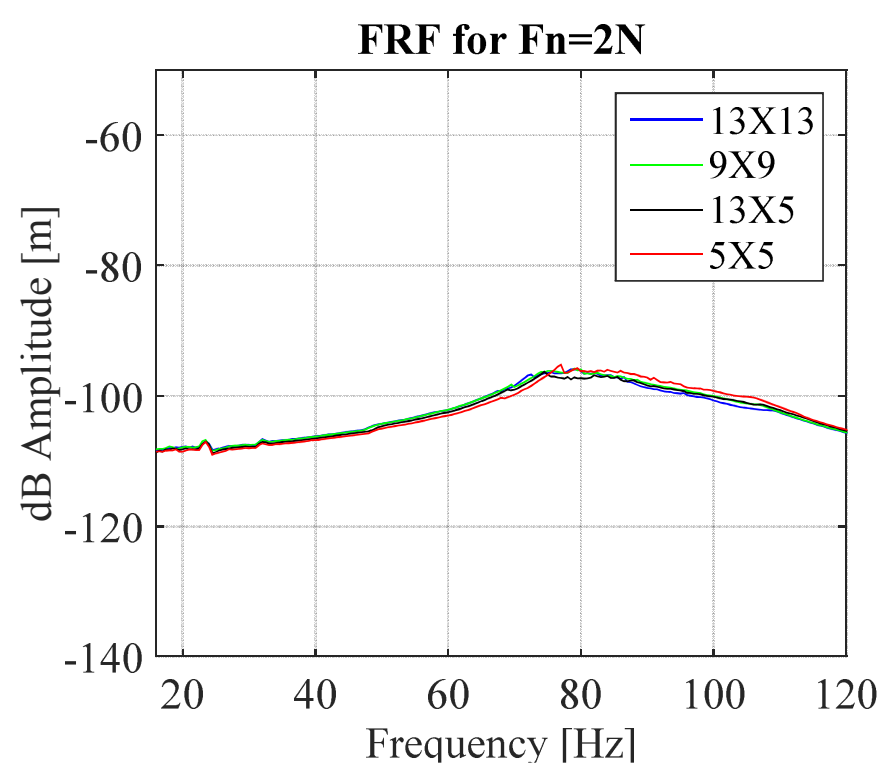

Figure 7: Area size influence on the FRFs for the smooth samples with Fn=2 N.

The overall effect of area size is illustrated in Tables 1 and 2 while the effect of roughness is shown in Tables 3 and 4 . Results reported concern surfaces $13 \times 13 \mathrm{~mm}^{2}$ and $5 \times 5 \mathrm{~mm}^{2}$. Discrepancies are illustrated via three quantities: maximum displacement amplitudes, frequency at which the maximum amplitudes are obtained and damping ratios.

\begin{tabular}{lcccc}
\hline & $\mathrm{Fn}=0.1 \mathrm{~N}$ & $\mathrm{Fn}=2 \mathrm{~N}$ & $\mathrm{Fn}=10 \mathrm{~N}$ & $\mathrm{Fn}=80 \mathrm{~N}$ \\
\hline $\begin{array}{l}\text { Amplitude differ- } \\
\text { ences. }\end{array}$ & $-5.2 \%$ & $0.7 \%$ & $1.5 \%$ & $0.8 \%$ \\
$\begin{array}{l}\text { Frequency at max } \\
\text { amplitudes. }\end{array}$ & $0 \%$ & $3 \%$ & $-1.1 \%$ & $0 \%$ \\
$\begin{array}{l}\text { Damping ratio } \\
\text { differences. }\end{array}$ & & $-0.44 \%$ & $0.91 \%$ & $0.27 \%$ \\
\hline
\end{tabular}

Table 1: Effect of area size: $13 \times 13 \mathrm{~mm}^{2}$ smooth versus $5 \times 5 \mathrm{~mm}^{2}$ smooth.

\begin{tabular}{lcccc}
\hline & $\mathrm{Fn}=0.1 \mathrm{~N}$ & $\mathrm{Fn}=2 \mathrm{~N}$ & $\mathrm{Fn}=10 \mathrm{~N}$ & $\mathrm{Fn}=80 \mathrm{~N}$ \\
\hline $\begin{array}{l}\text { Amplitude differ- } \\
\text { ences. }\end{array}$ & $4 \%$ & $1.7 \%$ & $1.3 \%$ & $3.3 \%$ \\
$\begin{array}{l}\text { Frequency at max } \\
\text { amplitudes. }\end{array}$ & $0 \%$ & $0 \%$ & $0 \%$ & $1.6 \%$ \\
$\begin{array}{l}\text { Damping ratio } \\
\text { differences. }\end{array}$ & $6.9 \%$ & $0.59 \%$ & $0.81 \%$ \\
\hline
\end{tabular}

Table 2: Effect of area size: $13 \times 13 \mathrm{~mm}^{2}$ rough versus $5 \times 5 \mathrm{~mm}^{2}$ rough.

As shown in Tables 1 and 2, discrepancies between surfaces $13 \times 13$ and $5 \times 5$ are limited. Variation in maximum displacement amplitudes does not exceed $5.2 \%$ and frequencies of the 
maximum amplitudes as well as damping are not affected significantly, with one exception for $\mathrm{Fn}=2 \mathrm{~N}$ with $6.9 \%$ discrepancy on damping.

\begin{tabular}{lcccc}
\hline & Fn=0.1 N & Fn=2 N & Fn=10 N & Fn=80 N \\
\hline $\begin{array}{l}\text { Amplitude differ- } \\
\text { ences. }\end{array}$ & $-0.31 \%$ & $2.4 \%$ & $0.85 \%$ & $-0.2 \%$ \\
$\begin{array}{l}\text { Frequency of the } \\
\text { maximum ampli- } \\
\text { tudes. }\end{array}$ & $0 \%$ & $5.8 \%$ & $2.8 \%$ & $1.6 \%$ \\
$\begin{array}{l}\text { Damping ratio } \\
\text { differences. }\end{array}$ & $-11.3 \%$ & $-1 \%$ & $0 \%$ \\
\hline
\end{tabular}

Table 3: Influence of roughness: $13 \times 13 \mathrm{~mm}^{2}$ smooth versus $13 \times 13 \mathrm{~mm}^{2}$ rough.

\begin{tabular}{lcccc}
\hline & $\mathrm{Fn}=0.1 \mathrm{~N}$ & $\mathrm{Fn}=2 \mathrm{~N}$ & $\mathrm{Fn}=10 \mathrm{~N}$ & $\mathrm{Fn}=80 \mathrm{~N}$ \\
\hline $\begin{array}{l}\text { Amplitude differ- } \\
\text { ences. }\end{array}$ & $8.4 \%$ & $-1.5 \%$ & $-1 \%$ & $2.32 \%$ \\
$\begin{array}{l}\text { Frequency of the } \\
\text { maximum ampli- }\end{array}$ & $0 \%$ & $5.8 \%$ & $4 \%$ & $1.6 \%$ \\
$\begin{array}{l}\text { tudes. } \\
\begin{array}{l}\text { Damping ratio dif- } \\
\text { ferences. }\end{array}\end{array}$ & $-4.1 \%$ & $-1.36 \%$ & $0.81 \%$ \\
\hline
\end{tabular}

Table 4: Influence of roughness: $5 \times 5 \mathrm{~mm}^{2}$ smooth versus $5 \times 5 \mathrm{~mm}^{2}$ rough.

The former conclusions remain when considering the effects of roughness on the dynamics of the assembly as shown in Tables 3 and 4.

\section{NUMERICAL MODELLING}

A finite element model of the structure has been constructed using beam, shell and 8 nodes brick elements. For the contact interface, zero thickness elements are used with Masing's tangential contact model. Masing's model is a combination of a Coulomb's contact model with a spring representing contact stiffness as illustrated in Figure 8 for a single dof mass-spring system. The tangential contact force $\mathrm{Ft}$ is given by:

$$
\begin{aligned}
& F_{t}=\operatorname{sgn}(\dot{x}) \mu F n \text { for slipping contact } \\
& F_{t}=-\operatorname{sgn}(\dot{x}) \mu F n+k_{d}(x-z) \text { for sticking contact }
\end{aligned}
$$

where $\mu$ is the friction coefficient, $F_{n}$ the normal contact load, $k_{d}$ the contact stiffness, $x$ the mass displacement, $\dot{x}$ its velocity and $\mathrm{z}$ the internal slipping variable. 


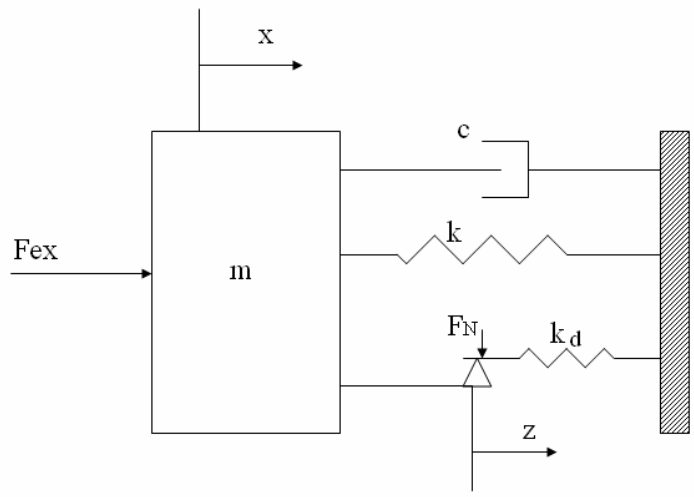

Figure 8: Masing's contact model in case of a 1 dof mass-spring system

Due to nonlinearity, solutions are obtained using a Newmark time integration scheme with Newton-Raphson iterations. Two different set of parameters $\left(\mu\right.$ and $\left.k_{d}\right)$ are considered. The first is obtained using model updating from experimental data. The second considers estimated averaged values obtained from [2], as in this reference authors suggest values representing a best compromise when experimental data are not available: friction coefficient of 0.66 and contact stiffness of $3 \mathrm{e} 7 \mathrm{~N} / \mathrm{m}$. Table 5 gives the parameters used for the smooth surface with an area of $13 \times 13 \mathrm{~mm}^{2}$ for models 1 and 2. Parameters suggested in [2] are higher than the identified values.

\begin{tabular}{lll}
\hline & Friction coefficient & Contact stiffness \\
\hline Model 1 & 0.45 & $3.9 \mathrm{e} 5 \mathrm{~N} / \mathrm{m}$ \\
Model 2 & 0.66 & $3 \mathrm{e} 7 \mathrm{~N} / \mathrm{m}$ \\
\hline
\end{tabular}

Table 5: Parameter for the smooth $13 \times 13 \mathrm{~mm}^{2}$ surface
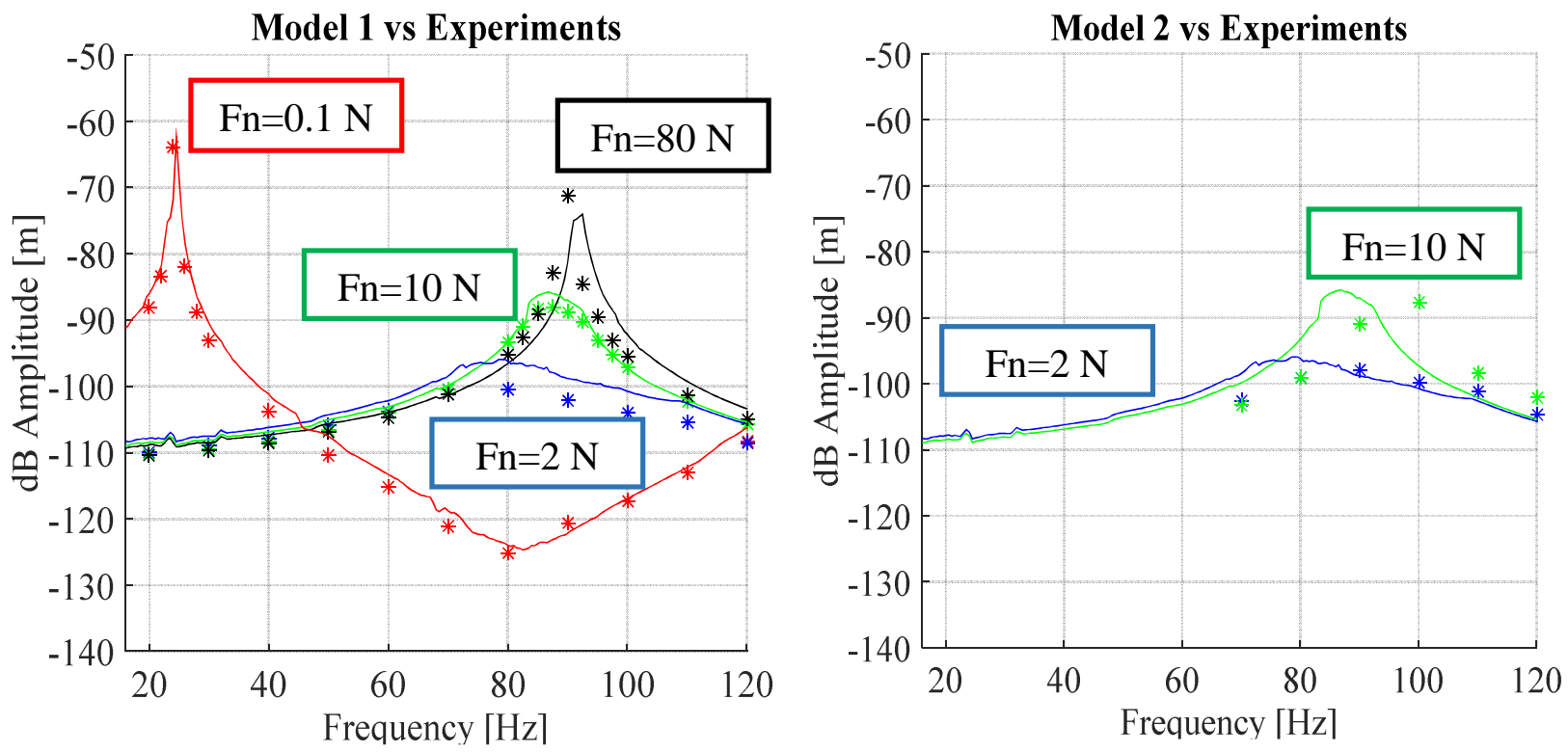

Figure 9: Models 1 and 2 versus experiments 
Figure 9 gives numerical and experimental results. In the case of model 2, comparisons are limited to two normal loads, due to calculation time. Results clearly show that model 1 reproduces with good accuracy the experimental FRFs while there is a shift of $10 \mathrm{~Hz}$ between model 2 and experiments. Minimal discrepancy is obtained when reaching the maximal displacement amplitudes for both models. A $10 \mathrm{~Hz}$ frequency shift is not dramatic considering that no experimental data is available, but illustrates the need for accurate parameter estimation.

Numerical studies were made for the other configurations of contact area size and roughness and confirm little to no influence of these parameters on the dynamic response of the assembly. An example of comparison between surface $13 \times 13$ and $5 \times 5$ is shown in Table 6 .

\begin{tabular}{lcccc}
\hline & $\mathrm{Fn}=0.1 \mathrm{~N}$ & $\mathrm{Fn}=2 \mathrm{~N}$ & $\mathrm{Fn}=10 \mathrm{~N}$ & $\mathrm{Fn}=80 \mathrm{~N}$ \\
\hline $\begin{array}{l}\text { Amplitude differ- } \\
\text { ences. }\end{array}$ & $0 \%$ & $1.4 \%$ & $2.2 \%$ & $-3.1 \%$ \\
$\begin{array}{l}\text { Frequency of max } \\
\text { amplitudes. }\end{array}$ & $0 \%$ & $0 \%$ & $0 \%$ & $0 \%$ \\
$\begin{array}{l}\text { Damping ratio dif- } \\
\text { ferences. }\end{array}$ & $1.7 \%$ & $1.6 \%$ & $0.23 \%$ \\
\hline
\end{tabular}

Table 6: Contact area size effect on the FRF - smooth $13 \times 13 \mathrm{~mm}^{2}$ versus smooth $5 \times 5 \mathrm{~mm}^{2}$

In order to examine a broader range of configurations, numerical calculations were performed for higher normal loads $(120-160-200 \mathrm{~N})$ and excitation loads $(2-20-40-100$ N). In Figure 10, smooth surface $13 \times 13$ and rough surface $13 \times 13$ are compared for $F n=120 \mathrm{~N}$ and Fex=40 N. The maximal amplitude discrepancy is $6.1 \%$ and it appears that the smooth surface dissipates significantly more energy than the rough one. Other calculations show an increase of the influence of contact characteristics for higher external loads (Fn and Fex). However, the observed discrepancies for maximum amplitude remain limited and do not exceed $10 \%$ for instance.
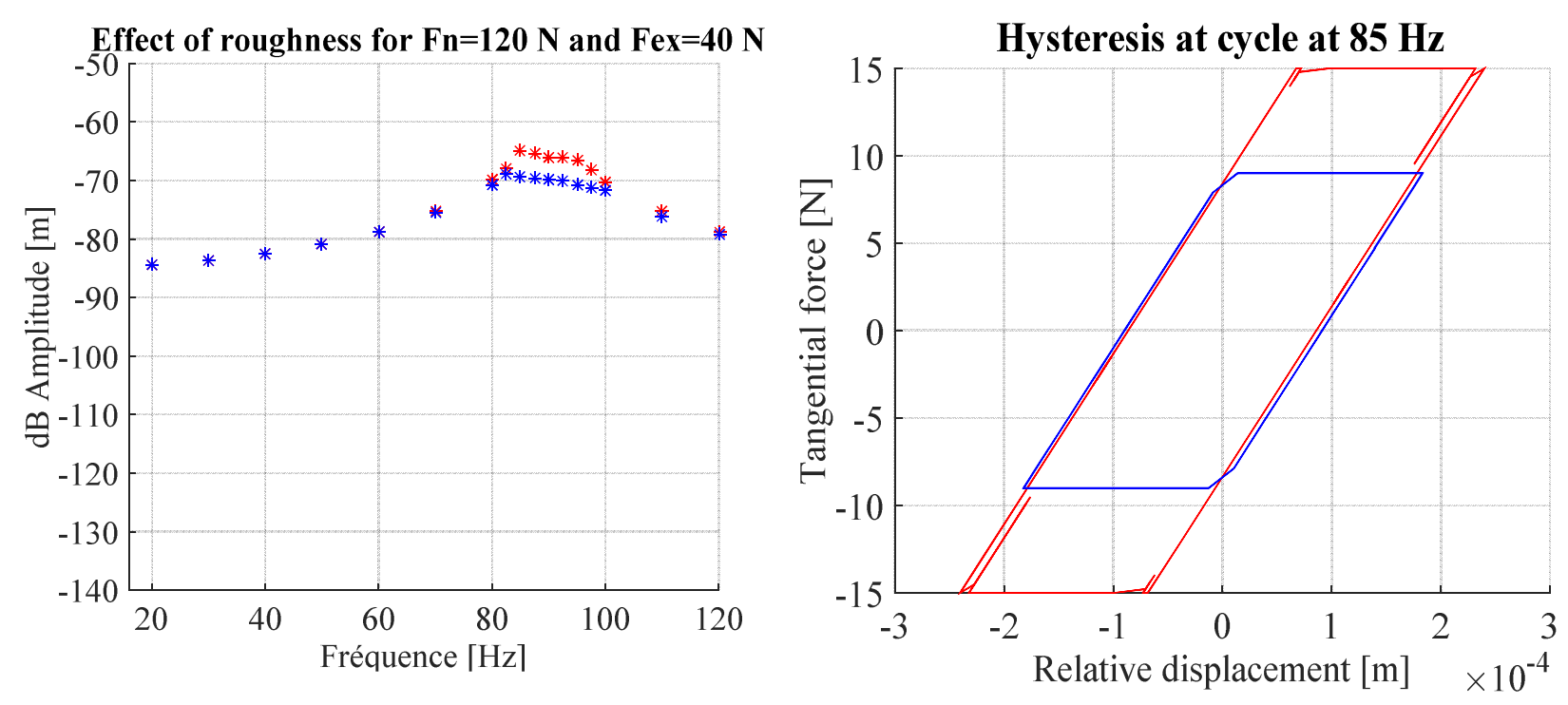

Figure 10: Smooth surfaces (red) versus rough surface (blue) for $13 \times 13$ sample, $F n=120 \mathrm{~N}$ and Fex=40 N. 


\section{CONCLUSIONS}

This study focuses on the dynamics of a beam associated with rubbing devices. Both experimental and numerical results are presented. Different configurations were tested in order to assess the effect of contact area size and roughness of the assembly. It was shown that the influence of such characteristics is limited when considering the discrepancies on maximum amplitude of displacements, frequencies of peak displacements and damping ratios. For the configurations considered, the behaviour remain globally in the frame of macro-slip.

Numerically, calculations with Masing's model were done. In the case where experimental data is available, the numerical model and experiments agree very well and confirm the fact that contact area and roughness have limited effects on the FRFs. On the other hand, when measured data are not available, the correlation between the model (using averaged estimated values) and experiments is more delicate as a shift between the peak frequencies is observed. This is due to the fact that the contact stiffness estimation is too high. However a good agreement was noticed for maximum amplitudes. This last results emphasize that work for a better estimation of contact parameters is still needed. A model which does not require prior experimental friction tests such as in [5] is under development.

\section{ACKNOWLEDGMENT}

This work has been carried out in the context of the FUI 2012-2015 SICODYN Project (pour des Simulations crédibles via la COrrélation calculs-essais et l'estimation d'incertitudes en DYNamique des structures). The authors would like to gratefully acknowledge the support of the FUI (Fonds Unique Interministériel).

\section{REFERENCES}

[1] C.W. Schwingshackl, E.P. Petrov, D.J. Ewins, Measured and estimated friction interface parameters in a nonlinear dynamic analysis. Mechanical Systems and Signal Processing, 28, 574-584, 2012.

[2] M. Eriten, A.A. Polycarpou, L.A. Bergman, Physics-based modeling for partial slip behavior of spherical contacts. International Journal of Solids and Structures, 47, 2554 2567, 2010.

[3] M. Eriten, A.A. Polycarpou, L.A. Bergman, Physics-based modeling for fretting behavior of nominally flat rough surfaces. International Journal of Solids and Structures, $\mathbf{4 8 ,}$ 1436-1450, 2011.

[4] M. Eriten, A.A. Polycarpou, L.A. Bergman, A Physics-Based Friction Model and Integration to a Simple Dynamical System. Journal of Vibration and Acoustics, 134, $051012,2012$.

[5] J. A. Greenwood, J. B. P. Williamson, Contact of Nominally Flat Surfaces. Proc. R. Soc. A, 295 (1442), 300-319, 1966.

[6] K. Johnson, Contact Mechanics, Cambridge University Press, Cambridge, 1985. 